\title{
Dimorphic Manifestations
}

By

\section{Yoshitaka Imai}

With 3 Text-Figures

Received February 19, 1935

The manifestation of a given hereditary unit or units is generally along one direction, although their manifold effects are common. The characters that are then being affected by ontogenic and environmental influences frequently fluctuate to a considerable extent. In some cases, however, the manifestation is dimorphic, although not based on any hereditary variation. It is a well known fact that the queen and the workers of social bees and ants are developed from like eggs but under different cares. In the present paper, however, dimorphism exhibited in plants will be considered.

The leaves of Juniperus chinensis are dimorphic, the one being the awl-shaped leaf and the other the scale-like leaf. The seedlings of this plant invariably bear awl leaves, succesive growths producing leaves of the same form, so that all young plants bear leaves of this form. Later, however, the branches bear the two leaf forms together when finally the old plants have nothing but scale leaves. The seeds are produced on branches having scale leaves. Intermediate, or transitive, forms between the awl and the scale leaves scarcely exist. According to NAKAI's observation (1918), J. procumbens, which generally has awl leaves, bears seeds also on the scale-leaved branches.

Since in Juniperus, dimorphism occurs as bud variation, its unit is a bud or a separate branch. Plants having leaves of both forms bear either awl- or scale-leaved buds, and when they develop into branches produce buds of either one of the two forms. Although bud variation due to dimorphic manifestations is a frequent occurrence, it does not occur in the part way of a branch of only a season's growth.

In its ontology, Linaria reticulata exhibits similar dimorphic variations (Fig. 1) to what has just been described. The autumn seedlings generally bear roundish leaves oppositely or verticillately attached to stems of stunted growth. However, some vigorous seedlings, which grow to a bush with several stems branched at the base of the main stem, have at the same time stems bearing linear leaves attached alternately. The stunted branches with short internodes present a dwarfish appearence in contrast to the tall branches with linear leaves. Although the dwarfed branches grow very slowly, the tall ones do so quickly in the spring sun, bearing in- 


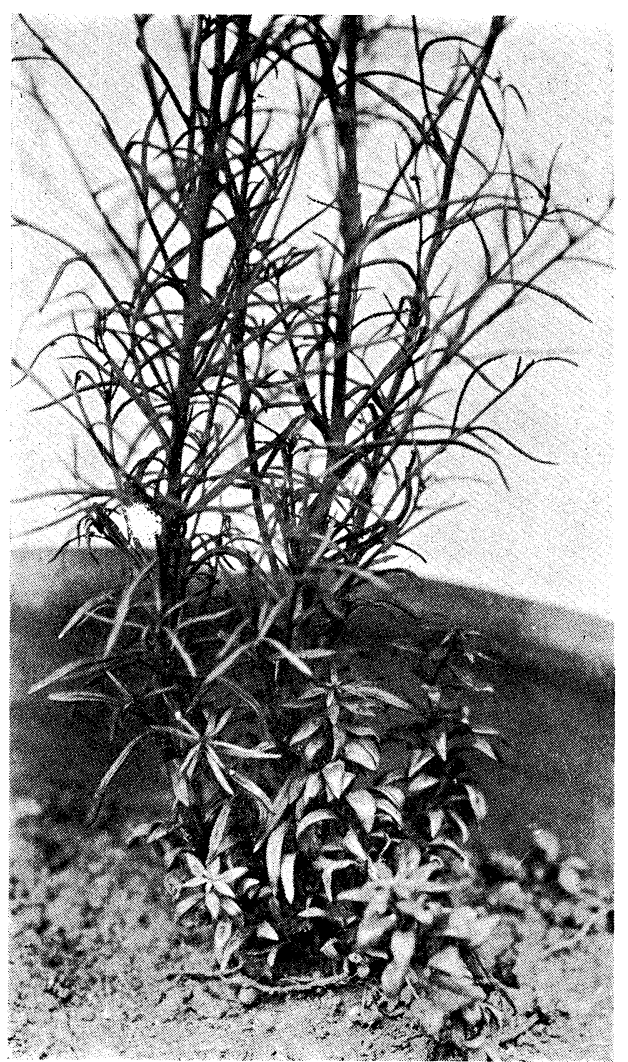

Fig. 1. Linaria reticutata

florescence on the stem. As a rule the seedlings eventually shoot out some tall branches. The dwarfed branches themselves do not produce flowers unless they bear tall branches. The dimorphic variation occurs in the leaf form, affecting also the arrangement of the leaves, the length of the stems, etc., in which case the unit of dimorphic manifestation is also bud, almost no intergrades being observed except in such cases as when some border leaves between the two sometimes exhibit inconsistent changes. Usually the dwarfed stems do not branch, but when they pinched they produce tall-typed branchlets through development of lateral buds. The change occurs from the dwarf type to the tall, but almost never the reverse, although the change is reversible in the stocks of Juniperus that bear

the two forms together. Unless it is branched, in both plants a stem bears one type of leaf form during its continuous growth. No one, I think, who is not acquainted with the subject, will say that the two types of Linaria, the dwarfed and the tall, are due to the same genotypic expression. Some trees, such as the apple, pear, ginkgo, pines, etc., bear two types of shoots, the ordinary long and the short. Since the fruits ripen generally on the short shoots in the apple, pear, ginkgo, etc., the significance of the short shoots has attracted the attention of fruit growers. In various pines, on the contrary, the flowers appear on the long shoots. In these cases also, dimorphism expresses itself in the bud as an unit. A horticultural strain of Pinus parviflora var. pentaphylla, called "Ikari-Matsu", has two types of leaves each in different short branches, the one short and the other long, with a sharp distinction between them (Fig. 2).

Phyllotaxy in the alternate leaves is either dextrose or sinistrose. Dimorphism, which occurs at random in the various branches of the same individual plant, displays no hereditary tendencies (I maI 1927).

Сомpтon (1913), who made statistical observations of the right-and 


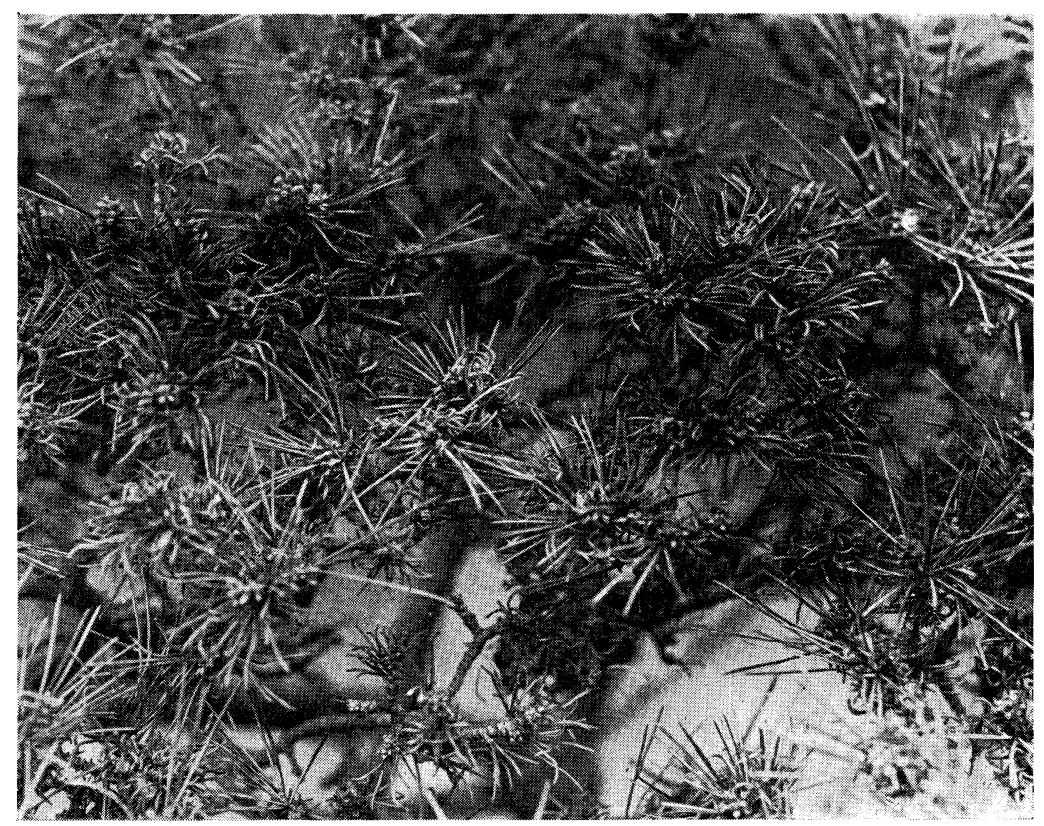

Fig. 2. Ikari-Matsu, a strain of Pinus parviflora var. pentaphylla

left-handedness of the first leaves of seedlings in some cereals, found that the numbers of the two forms of seedlings are nearly equal, thus presenting chance manifestation. In Zea Mays, however, a difference was detected in the seedlings that came from the seeds of the odd and the even orthostichies, which he attributed to mechanical causes in their early ontogeny, due to differences in the spatial relationships of the embryos on the cob.

Studying the contorta form of Plantago major var. asiatica, Ineno (1923) showed that the two types of rosettes, with dextrose and sinistrose leaves, occur in equal numbers, indicating a case of chance manifestation. Prior to this, DE VRIEs (1903) observed the torsion of the stems in Dipsacus silvestris, and KORIBA(1914) the spiral inflorescence in Spiranthes australis. Although in these cases, the mode of winding differs with the individual plant; strictly speaking, dimorphism seems to oceur with the bud as unit, but not with the individual as unit. When two or more shoots are produced on the same individual, the two forms must have occurred by chance.

In the diecious plant, Arisaema japonicum, Maekawa (1924) showed that the pistilate and staminate individuals occur according as the degree of nutrition in their corms differ, whence it follows that the extent of nutrition controls dimorphic manifestation so far as sex differentiation of the flowers is concerned.

In these cases, in which probably even Arisaema is included, dimorphism occurs or seems to occur in a bud as an unit. Since the growing 
point of a bud is composed of multicelluar initial cells, the determination of its character should be considered as having to do with the massive cells collectively as an unit, although the exact mechanism of determination is not clear. The differentiation is continued through the growth of the bud and the inertia renewed at the formation of an apical or lateral bud. Dimorphic differentiation occurs either at random or under ontogenic and other influences. The inertia, however, is sometimes partially deferred, thus affecting the form of the buds under ontogenic influences; for example, in Juniperus, the form changes at times into the scale form, but the reverse happens less frequently, while in Linaria, the dwarf form tends strongly to change into the tall form with almost no reversed cases. In Pinus, the apical and its accessory buds grow to long branches, but the lateral ones to short branches. The dormant growing points of short branches may develop into long branches by accidental or artificial stimulation. The mode of dimorphic manifestations in this case is rather regular under ontogenic control.

In some cases, however, dimorphic manifestations may occur at any stage of ontogeny, or the time of manifestation may be indefinite. For instance, the leaves of Ranunculus acquatilis are known to exhibit two forms according to the influence of water, the aerial leaves being roundish and the submerged leaves being finely serrated. The two types seems to be determined by environmental influence at any stage of ontogeny. Dimorphism of the aerial and submerged leaves are known in other plants, such as Limnophila heterophylla, Polygonum amphibium, Proserpinaca palustris, Radicula aquatica, Ranunculus sceleratus, Trapa natans, etc.

\section{Conclusion}

The plant life cycle alternates between the haploid and diploid generations (Fig. 3A), the mode in which a hereditary unit or units manifest themselves generally being in only one direction. When mutation occurs, a new life cycle with a different hereditary constitution arises (Fig. 3B). Dimorphic manifestations are then expressed by two transformable modes of life cycles (Fig. 3C). The unit of dimorphic manifestations being a bud, in the growth of a bud a given character continues until it branches or forms new buds. The inertia is generally lost when stem growth ceases, a new chance for dimorphism occurring on the formation of a bud. The time of manifestation is indefinite in the leaf form of some aquatic or amphibious plants in which external condition determine its expression. This case is also explained by Fig. 3C. The dimorphism in the cases observed in Juniperus and Linaria are closely related to the ontogeny of the plant body. Taking Linaria, for example, its life cycle beginning with 
the egg, proceeds to the dwarf type and after passing through the tall type, returns to gametophytic generation (Fig. 3D).
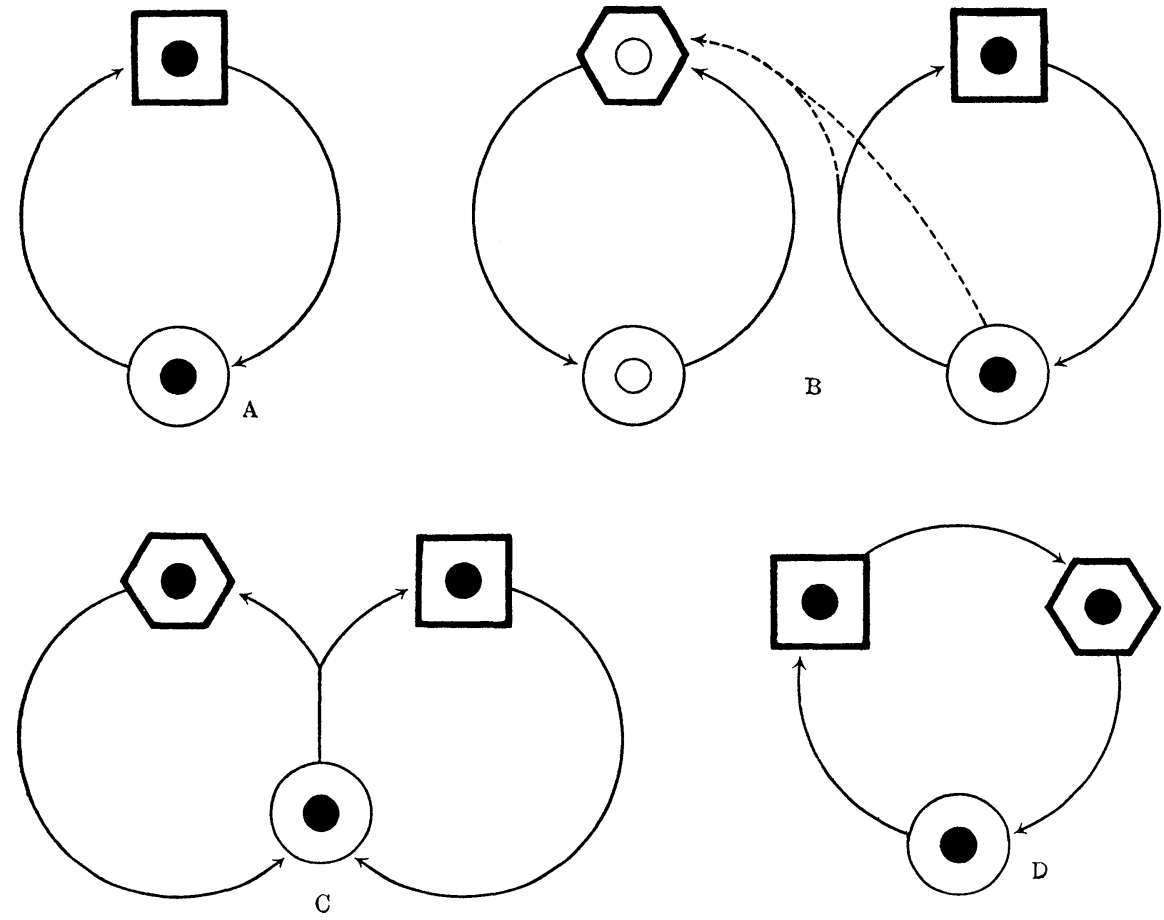

Fig. 3. Diagrammatic representation of life cycle. A, a standard case. The small circle indicates an egg-cell and the square opposite it the differentiated individual or branch. The black nucleus is the hereditary substance contained in the cell. $\mathrm{B}$, the case in which a mutant (indicated by hexagon) arises with altered hereditary substance (indicated by white nucleus). C, dimorphic manifestations expressed by the same hereditary substance. $\mathrm{D}$, dimorphic manifestations occurring successively, one to another, on which the sexual organs are developed.

\section{References}

Compton, R. H. 1913. A further contribution to the study of right-and left-handedness. Jour. Genetics, 2: 53-70.

Ikeno, S. 1923. Erblichkeitsversuche an einigen Sippen von Plantago major. Jap. Jour. Bot., 1: 153-212.

ImaI, Y. 1927. The right- and left-handedness of phyllotaxy. Bot. Magazine (Tokyo), $41592-596$.

KorIBA, K. 1914. Mechanisch-physiologische Studien über die Drehung der SpiranthesÄhre. Jour. Coll. Sei., Imp. Univ. Tokyo, 36, 3: 1-179.

MaekaWa, T. 1924. On the phenomena of sex transition in Arisaema japonicum Bl. Jour. Coll. Agri., Hokkaido Imp. Univ., 13: 217-305.

NakaI, T. 1918. Dimorphic leaves of Juniperus procumbens, Sieb. Bot. Magazine (Tokyo), 32: 76-77. In Japanese.

VRIES, H. DE 1903. Die Mutationstheorie. Bd 2. Leipzig, Veit \& Comp. 